\title{
Identification of specific and common diagnostic antibody markers for gastrointestinal cancers by SEREX screening using testis cDNA phage library
}

\author{
Sohei Kobayashi'1,2, Takaki Hiwasa ${ }^{3}$, Takahiro Arasawa1,3, Akiko Kagaya ${ }^{3,4}$, Sayaka \\ Ishii $^{1,3}$, Hideaki Shimada5, Masaaki Ito5, Masae Suzuki,1,3, Masayuki Kano ${ }^{1}$, Bahityar \\ Rahmutulla $^{6}$, Kouichi Kitamura ${ }^{2,7}$, Yuji Sawabe ${ }^{2}$, Hideo Shin', Masaki Takiguchi ${ }^{3}$, \\ Fumio Nomura9, Hisahiro Matsubara ${ }^{1}$ and Kazuyuki Matsushita \\ ${ }^{1}$ Department of Frontier Surgery, Graduate School of Medicine, Chiba University, Chiba 260-8670, Japan \\ ${ }^{2}$ Department of Laboratory Medicine \& Division of Clinical Genetics and Proteomics, Chiba University Hospital, Chiba 260- \\ 8670, Japan \\ ${ }^{3}$ Department of Biochemistry and Genetics, Graduate School of Medicine, Chiba University, Chiba 260-8670, Japan \\ ${ }^{4}$ Clinical Research Center, Chiba University Hospital, Chiba 260-8670, Japan \\ ${ }^{5}$ Department of Gastroenterological Surgery, School of Medicine, Toho University, Tokyo 143-8541, Japan \\ ${ }^{6}$ Department of Molecular Oncology, Graduate School of Medicine, Chiba University, Chiba 260-8670, Japan \\ ${ }^{7}$ Department of Molecular Diagnosis, Graduate School of Medicine, Chiba University, Chiba 260-8670, Japan \\ ${ }^{8}$ Department of Neurosurgery, Higashi Funabashi Hospital, Chiba 274-0065, Japan \\ ${ }^{9}$ Divisions of Clinical Mass Spectrometry and Clinical Genetics, Chiba University Hospital, Chiba 260-8670, Japan \\ Correspondence to: Kazuyuki Matsushita, email: kmatsu@faculty.chiba-u.jp \\ Keywords: cancer-testis antigen; SEREX; esophageal squamous cell carcinoma; AlphaLISA; gastrointestinal cancers \\ Received: December 27, $2017 \quad$ Accepted: March 07, $2018 \quad$ Published: April 06, 2018 \\ Copyright: Kobayashi et al. This is an open-access article distributed under the terms of the Creative Commons Attribution License \\ 3.0 (CC BY 3.0), which permits unrestricted use, distribution, and reproduction in any medium, provided the original author and \\ source are credited.
}

\section{ABSTRACT}

The present study was planned to identify novel serum antibody markers for digestive organ cancers. We have used screening by phage expression cloning and identified novel fourteen antigens in this experiment. The presence of autoantibodies against these antigens in serum specimens was confirmed by western blotting. As for auto-antibodies against fourteen antigens, AlphaLISA (amplified luminescence proximity homogeneous assay) assay was performed in the sera of gastrointestinal cancers patients to confirm the results. Serum antibody levels against these fourteen recombinant proteins as antigens between healthy donors (HD) and esophageal squamous cell carcinoma (ESCC) patients, gastric cancer (GC), or colon cancer (CC) were compared. The serum levels of all fourteen auto-antibodies were significantly higher in ESCC and GC than those of HD. Among those auto-antibodies, except ECSA2 and CCNL2, were also detected significantly higher levels in CC than those of HD. Receiver operating curve (ROC) revealed similar results except CCNL2 in CC. AUC values calculated by ROC were higher than 0.7 in auto-antibodies against TPI1, HOOK2, PUF60, PRDX4, HS3ST1, TUBA1B, TACSTD2, AKR1C3, BAMBI, DCAF15 in ESCC, auto-antibodies against TPI1, HOOK2, PUF60, PRDX4, TACSTD2, AKR1C3, BAMBI, DCAF15 in GC, and auto-antibodies against TPI1, HOOK2, PUF60 in CC. AUC of the combination of HOOK2 and anti-p53 antibodies in ESCC was observed to be as high as $\mathbf{0 . 8 2 2 8}$. Higher serum antibody levels against ten antigens could be potential 


\section{diagnostic tool for ESCC. Higher serum antibody levels against eight antigens could be potential diagnostic tool for GC, and serum antibody levels against three antigens could be potential diagnostic tool for $\mathrm{CC}$.}

\section{INTRODUCTION}

There is a specific common mechanism of expressing some molecules (e.g., CEA) (these have been confirmed to be expressed in embryonic stage) during gastrointestinal tumorigenesis. However, there are few diagnostic biomarkers that are able to specifically detect and discriminate various cancers at an early stage. Recent research in the field of cancer therapeutic strategy suggests that there are few biomarker candidates that are able to predict the therapeutic effects. Moreover, these could also function as companion diagnostic tools [1]. The recently developed serum anti-p53 antibodies test was useful for the detection of superficial ESCC [2]. As positive rate of serum anti-p53 antibody was around $30 \%$, other serum antibodies were necessary for a combinational test to improve positive rate and diagnostic accuracy.

The serological identification of antigens by recombinant cDNA expression cloning (SEREX) is an effective screening method for identification of serum antibody-type tumor markers [3]. SEREX could be utilized for the immune-screening of cDNA libraries prepared from tumor specimens with either autologous or allogeneic sera. Furthermore, sequencing the isolated cDNA clones easily identified antigens. This made SEREX suitable for the large-scale screening of tumor antigens. SEREX has been applied to various human tumor types and has identified more than 1000 novel tumor antigens (SEREX antigens) [4]. We have previously performed large-scale SEREX screenings and identified numerous ESCC SEREX antigens. Furthermore, 21 antigens were reported to have included the tumor suppressor p53, the oncoproteins phosphatidylinositol 3-kinase, and stathmin [5-13]. Anti-p53 antibody marker has been utilized for not only ESCC but also gastric cancer (GC) as well as colon cancer (CC). Further, the antibody levels against other SEREX antigens might be responsible for GC and CC. Thus, we examined whether antibody markers against ESCC SEREX antigens were common among digestive organ cancers.

\section{RESULTS}

\section{Identification of SEREX antigens recognized by sera of patients with ESCC}

Expression cloning using the sera of patients with ESCC has identified 14 clones. Some of these clones were identified using $\lambda$ ZAP II library. They were triosephosphate isomerase 1 (TPI1) (Accession number: NM_000365), hook microtubule-tethering protein 2 (HOOK2) (Accession number: NM_001100176) [9,
11], peroxiredoxin 4 (PRDX4) (Accession number: NM_006406), heparan sulfate (glucosamine) 3-O-sulfotransferase 1 (HS3ST1) (Accession number: NM_005114), tubulin alpha-1B (TUBA1B) (Accession number: NM 006082), tumor-associated calcium signal transducer 2 (TACSTD) (Accession number: NM_002353) [5, 9], aldo-keto reductase family 1 member C3 (AKR1C3) (Accession number: NM_003739), BMP and activin membrane-bound inhibitor homolog (BAMBI) (Accession number: NM_012342), DDB1- and CUL4associated factor 15 (DCAF1) (Accession number: NM_138353), phosphodiesterase 4D-interacting protein (PDE4DIP) (Accession number: NM_001198834) [10], esophageal carcinoma SEREX antigen-1 (ECSA1) [11], ECSA2 [11], cyclin L2 (CCNL2) (Accession number: NM_030937) [10, 12], and poly(U) binding splicing factor 60 (PUF60) (Accession number: NM 078480.2) $[1,13,14]$. TPI1, PRDX4, HS3ST1, TUBA1B, AKP1C3, BAMBI, and DCAF1 were identified using testis cDNA library. However, they have not yet been reported. Recombinant proteins were expressed in E. coli as GST-fusion proteins and were purified by affinitychromatography using Glutathione Sepharose.

\section{Confirmation of the presence of serum antibodies in patients with ESCC by western blotting}

The western blotting analysis confirmed the presence of auto-antibodies in the sera of patients. GSTTPI1, GST-HOOK2, GST-PRDX4, GST-HS3ST1, GSTTUBA1B, GST-TACSTD, GST-AKP1C3, GST-BAMBI, GST-DCAF1, GST-PDE4DIP, GST-ECSA1, GST-ECSA2, GST-CCNL2, and GST-PUF60 as well as GST proteins were recognized by anti-GST antibody as reactions of $27 \mathrm{kDa}, 83 \mathrm{kDa}, 60 \mathrm{kDa}, 36 \mathrm{kDa}, 29 \mathrm{kDa}, 45 \mathrm{kDa}, 63$ $\mathrm{kDa}, 58 \mathrm{kDa}, 60 \mathrm{kDa}, 130 \mathrm{kDa}, 36 \mathrm{kDa}, 40 \mathrm{kDa}, 25 \mathrm{kDa}$, $36 \mathrm{kDa}$, and $28-\mathrm{kDa}$ proteins, respectively (Figure 1). On the contrary, only GST-ECSA1 or GST-ECSA2 was reacted with the serum antibodies of patients 14 and 17, respectively (Supplementary Figures 1A, 1B). Serum 19 showed the reactivity to TPI1 and HOOK2, which eventually enabled the recognition of both GST-TPI1 and GST-HOOK2 (Supplementary Figure 1C). Serum 20 showed the reactivity to AKP1C3, thereby it enabled the recognition of GST-AKP1C3 (Supplementary Figure 1D).

\section{Auto-antibody levels showed increase in patients with digestive organ cancers}

We examined the levels of serum auto-antibodies using the sera of HD and patients with ESCC, GC, 
and CC procured from Chiba University Hospital. HD subjects from Higashi Funabashi Hospital were selected as healthy volunteers. The results of AlphaLISA showed that the levels of TPI1-Abs, HOOK2-Abs, PUF60Abs, PRDX4-Abs, HS3ST1-Abs, TACSTD2-Abs, TUBA1B-Abs, AKR1C3-Abs, BAMBI-Abs, DCAF15Abs, PDE4DIP-Abs, ECSA1-Abs, ECSA2-Abs, and CNNL2-Abs were significantly higher in patients with ESCC, GC, or CC than in HD (Figures $2 \mathrm{~A}-2 \mathrm{~F}$ and Supplementary Figures 2A-2H). The cutoff value was determined as the average + 2SD of HD, to keep the $95 \%$ confidence interval. Receiver operating curve (ROC) analysis was carried out to evaluate the ability of these markers to detect ESCC, GC, and CC. The areas under the curve (AUCs) of TPI1, HOOK2, PUF60, PRDX4, HS3ST1, TUBA1B, TACSTD2, AKR1C3, BAMBI, and DCAF15 for ESCC were significantly larger than 0.700 (Table 1). The highest AUC values were obtained for HOOK2 when compared with AUC values of ESCC.
AUCs for GC were TPI1, HOOK2, PUF60, PRDX4, TACSTD2, AKR1C3, BAMBI and DCAF15 by larger than 0.700 respectively, whereas those for $\mathrm{CC}$ were TPI1, HOOK2, PUF60 by larger than 0.700 respectively (Figure 3A and Table 1). Next, gastrointestinal cancers were classified into early or advanced stages. Higher level of antibodies in early stages than in advanced stages cancers were shown. In AUC of ESCC showed BAMBI-0.7741, AKR1C3-0.7702, PRDX4-0.7684 (Figure 3B). In AUC of GC showed HOOK20.7831, TP11-0.7714, BAMBI-0.7563 (Figure 3C). In AUC of CC showed TP11-0.7513, PUF60-0.7199, TACSTD2-0.6769 (Figure 3D).

\section{Combined ROC curve increases AUC}

The receiver operating combined curve (ROC) analysis was carried out to evaluate the facility of these markers to detect ESCC, GC, and CC (Figure 4 and

\section{Anti-GST antibodies}

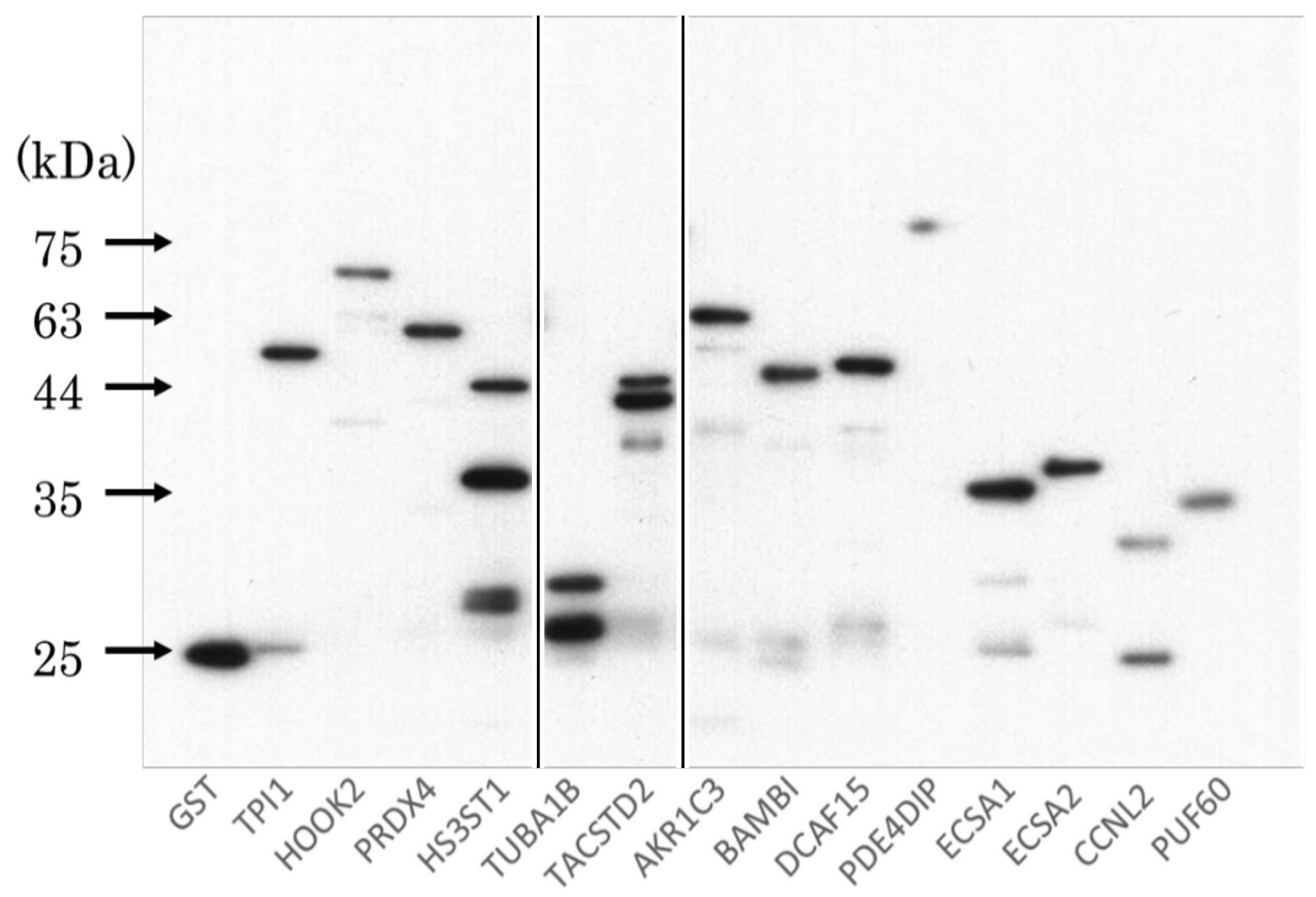

Figure 1: The presence of 14-antigens in patients with anti-GST antibodies. To purify the SEREX-identified proteins, the insertion sequences of the 14 pBluescript plasmids were ligated in-frame into GST-tagged expression vectors. We confirmed by sequence analysis that the recombinant pGEX-4T-3 plasmids were properly recombined and GST-tagged recombinant proteins were affinity-purified using glutathione-Sepharose. To confirm the recombinant proteins to be the GST-tagged one that react with autologous plasma, the proteins were lysed in a SDS sample buffer, incubated at $100^{\circ} \mathrm{C}$ for $3 \mathrm{~min}$, Affinity-purified GST-tagged antigens were separated on $11 \%$ SDSpolyacrylamide gels followed by Western blot using anti-GST antibody. All samples were examined simultaneously, at the same time on the same membrane. 
Supplementary Figure 3). The antibodies with CEA, only the AUC of DCAF15+CEA increased to 0.7223 in ESCC (Figure 4A and Supplementary Figure 3A). However, the AUC of TPI1+CEA decreased to 0.7435 in GC (Figure $4 \mathrm{~B}$ and Supplementary Figure 3B). Further, in CC, HOOK2+CEA showed AUC of 0.8075 (Figure 4C and Supplementary Figure 3C). The AUC of all the antibodies combined with anti-p53 antibody, HOOK2 and BAMBI showed 0.8228 in ESCC (Figure 4D and Supplementary Figure 3D). There was no antibody indicating AUC larger than 0.800 in CC (Figure 4E and Supplementary Figure $3 \mathrm{E})$. The AUC was summarized in early or advanced stages cancers were showed in Table 2. Advanced stage cancers showed higher AUC than that of early stage cancers. Further, in ESCC and CC, the efficiency of early diagnosis was increased when combined with $\mathrm{HOOK} 2$ and anti-p53 antibody (AUC of ESCC: 0.7985, AUC of CC: $0.7669)$.

\section{DISCUSSION}

We have identified novel potential diagnostic markers for digestive organ cancers by SEREX screening. Those serum antibody markers were detected using purified GST-fusion proteins as antigen. Two hundred seventy-seven patients with various cancers were evaluated for the presence of various-Abs. Patients with confirmed digestive organ cancers demonstrated


Figure 2: Comparison of levels of antibodies against top 6 SEREX antigens. The levels of antibodies against TPI1, HOOK2, PUF60, PRDX4, AKR1C3, and BAMBI in healthy donors (HD), gastric cancer (GC), colon cancer (CC), and esophageal SCC (ESCC) examined by AlphaLISA are shown. Serum antibody levels examined by AlphalLISA are shown by a box-whisker plot. The box plots display the 10th, 20th, 50th, 80th and 90th percentiles. P values as compared to the HD specimens are shown. P values were calculated by Mann-Whitney U test. 
Table 1: Receiver operating curve (ROC) analysis of auto-antibodies examined in the sera of gastrointestinal cancers

\begin{tabular}{|c|c|c|c|c|c|c|c|c|c|c|c|c|}
\hline & \multicolumn{4}{|c|}{ ESCC } & \multicolumn{4}{|c|}{ GC } & \multicolumn{4}{|c|}{$\mathrm{CC}$} \\
\hline & Area & SE & $95 \%$ CI & $P$ value & Area & SE & $95 \%$ CI & $P$ value & Area & SE & $95 \% \mathrm{CI}$ & $P$ value \\
\hline HOOK2 & 0.8001 & 0.0324 & $\begin{array}{c}0.7366 \\
\text { to } \\
0.8637\end{array}$ & $<0.0001$ & 0.7695 & 0.0343 & $\begin{array}{c}0.7022 \\
\text { to } \\
0.8367\end{array}$ & $<0.0001$ & 0.7577 & 0.0343 & $\begin{array}{c}0.6905 \\
\text { to } \\
0.8249\end{array}$ & $<0.0001$ \\
\hline BAMBI & 0.7664 & 0.0366 & $\begin{array}{c}0.6947 \\
\text { to } \\
0.8381\end{array}$ & $<0.0001$ & 0.7403 & 0.0358 & $\begin{array}{c}0.6701 \\
\text { to } \\
0.8105\end{array}$ & $<0.0001$ & 0.6883 & 0.0378 & $\begin{array}{c}0.6142 \\
\text { to } \\
0.7624\end{array}$ & $<0.0001$ \\
\hline PRDX4 & 0.7654 & 0.0353 & $\begin{array}{c}0.6962 \\
\text { to } \\
0.8347\end{array}$ & $<0.0001$ & 0.7221 & 0.0367 & $\begin{array}{c}0.6502 \\
\text { to } \\
0.7939\end{array}$ & $<0.0001$ & 0.6841 & 0.0380 & $\begin{array}{c}0.6097 \\
\text { to } \\
0.7585\end{array}$ & $<0.0001$ \\
\hline AKR1C3 & 0.7643 & 0.0363 & $\begin{array}{c}0.6931 \\
\text { to } \\
0.8355\end{array}$ & $<0.0001$ & 0.7393 & 0.0360 & $\begin{array}{c}0.6688 \\
\text { to } \\
0.8099\end{array}$ & $<0.0001$ & 0.6803 & 0.0381 & $\begin{array}{c}0.6055 \\
\text { to } \\
0.7550\end{array}$ & $<0.0001$ \\
\hline PUF60 & 0.7428 & 0.0368 & $\begin{array}{c}0.6706 \\
\text { to } \\
0.8151\end{array}$ & $<0.0001$ & 0.7231 & 0.0370 & $\begin{array}{c}0.6507 \\
\text { to } \\
0.7956\end{array}$ & $<0.0001$ & 0.7075 & 0.0377 & $\begin{array}{c}0.6336 \\
\text { to } \\
0.7815\end{array}$ & $<0.0001$ \\
\hline HS3ST1 & 0.7398 & 0.0374 & $\begin{array}{c}0.6665 \\
\text { to } \\
0.8130\end{array}$ & $<0.0001$ & 0.6805 & 0.0383 & $\begin{array}{c}0.6054 \\
\text { to } \\
0.7556\end{array}$ & $<0.0001$ & 0.6165 & 0.0404 & $\begin{array}{c}0.5372 \\
\text { to } \\
0.6957\end{array}$ & 0.0052 \\
\hline TUBA1B & 0.7227 & 0.0378 & $\begin{array}{c}0.6486 \\
\text { to } \\
0.7969\end{array}$ & $<0.0001$ & 0.6384 & 0.0398 & $\begin{array}{c}0.5603 \\
\text { to } \\
0.7165\end{array}$ & 0.0009 & 0.5891 & 0.0408 & $\begin{array}{c}0.5090 \\
\text { to } \\
0.6691\end{array}$ & 0.0325 \\
\hline TPI1 & 0.7218 & 0.0373 & $\begin{array}{c}0.6486 \\
\text { to } \\
0.7949\end{array}$ & $<0.0001$ & 0.7470 & 0.0354 & $\begin{array}{c}0.6777 \\
\text { to } \\
0.8163\end{array}$ & $<0.0001$ & 0.7389 & 0.0356 & $\begin{array}{c}0.6692 \\
\text { to } \\
0.8086\end{array}$ & $<0.0001$ \\
\hline DCAF15 & 0.7209 & 0.0381 & $\begin{array}{c}0.6462 \\
\text { to } \\
0.7955\end{array}$ & $<0.0001$ & 0.7131 & 0.0370 & $\begin{array}{c}0.6405 \\
\text { to } \\
0.7856\end{array}$ & $<0.0001$ & 0.6564 & 0.0391 & $\begin{array}{c}0.5798 \\
\text { to } \\
0.7329\end{array}$ & 0.0002 \\
\hline TACSTD2 & 0.7119 & 0.0385 & $\begin{array}{c}0.6363 \\
\text { to } \\
0.7874\end{array}$ & $<0.0001$ & 0.7348 & 0.0361 & $\begin{array}{c}0.6640 \\
\text { to } \\
0.8056\end{array}$ & $<0.0001$ & 0.6691 & 0.0391 & $\begin{array}{c}0.5925 \\
\text { to } \\
0.7457\end{array}$ & $<0.0001$ \\
\hline PDE4DIP & 0.6875 & 0.0398 & $\begin{array}{c}0.6095 \\
\text { to } \\
0.7655\end{array}$ & $<0.0001$ & 0.6960 & 0.0377 & $\begin{array}{c}0.6220 \\
\text { to } \\
0.7700\end{array}$ & $<0.0001$ & 0.6459 & 0.0397 & $\begin{array}{c}0.5680 \\
\text { to } \\
0.7238\end{array}$ & 0.0005 \\
\hline ECSA1 & 0.6797 & 0.0396 & $\begin{array}{c}0.6021 \\
\text { to } \\
0.7572\end{array}$ & $<0.0001$ & 0.6687 & 0.0389 & $\begin{array}{c}0.5926 \\
\text { to } \\
0.7449\end{array}$ & $<0.0001$ & 0.6247 & 0.0401 & $\begin{array}{c}0.5461 \\
\text { to } \\
0.7033\end{array}$ & 0.0028 \\
\hline ECSA2 & 0.6257 & 0.0417 & $\begin{array}{c}0.5439 \\
\text { to } \\
0.7075\end{array}$ & 0.0035 & 0.6354 & 0.0404 & $\begin{array}{c}0.5561 \\
\text { to } \\
0.7147\end{array}$ & 0.0012 & 0.5889 & 0.0414 & $\begin{array}{c}0.5077 \\
\text { to } \\
0.6701\end{array}$ & 0.0329 \\
\hline CCNL2 & 0.6179 & 0.0420 & $\begin{array}{c}0.5355 \\
\text { to } \\
0.7003\end{array}$ & 0.0062 & 0.6092 & 0.0410 & $\begin{array}{c}0.5289 \\
\text { to } \\
0.6896\end{array}$ & 0.0090 & 0.5464 & 0.0418 & $\begin{array}{c}0.4644 \\
\text { to } \\
0.6284\end{array}$ & 0.2655 \\
\hline
\end{tabular}

SE: Standard error.

95\% CI: Adjusted 95\% confidence interval.

$P$ value: Mann-Whitney $U$ test.

$>0.700 \quad>0.750$. 
significantly higher levels of the antibodies against most ESCC SEREX antigens. This suggested that ESCC, GC, and $\mathrm{CC}$ have a common carcinogenesis process. However, some of the antibody markers showed differential antibody levels, i.e., all 14 markers were significantly higher in patients with ESCC or GC in comparison to those in HDs. On the contrary, the levels of ECSA2-Ab and CCNL2$\mathrm{Ab}$ were not significantly different between patients with $\mathrm{CC}$ and HDs (Figure 2 and Supplementary Figure 2). Similar results were also attained by ROC analysis. The AUCs were higher than 0.6 for most of the markers except ECSA2 and CCNL2 in comparison to CC (Table 1). Also, the AUCs higher than 0.7 were observed for ten markers versus ESCC, eight markers versus GC, and three markers versus CC. Thus, tumor nature of ESCC might be more similar to GC than to $\mathrm{CC}$. It is conceivable that HOOK2$\mathrm{Ab}$, PUF60-Ab, and TPI1-Ab are common markers for digestive organ cancers.

Furthermore, the combined ROC analysis of antibodies with anti-p53 antibody, and CEA showed elevation in AUCs of almost antibodies in various cancers. The combinations of anti-p53 antibody and HOOK2 markers were valuable for early detection of ESCC and CC (Figure 4 and Table 2). Therefore, the combination of antibodies with anti-p53 antibody and CEA is a potential approach for the diagnosis of digestive organ cancers. However, prospective multi-institutional studies comparing the sensitivity and specificity of this combinational detection approach are necessary.
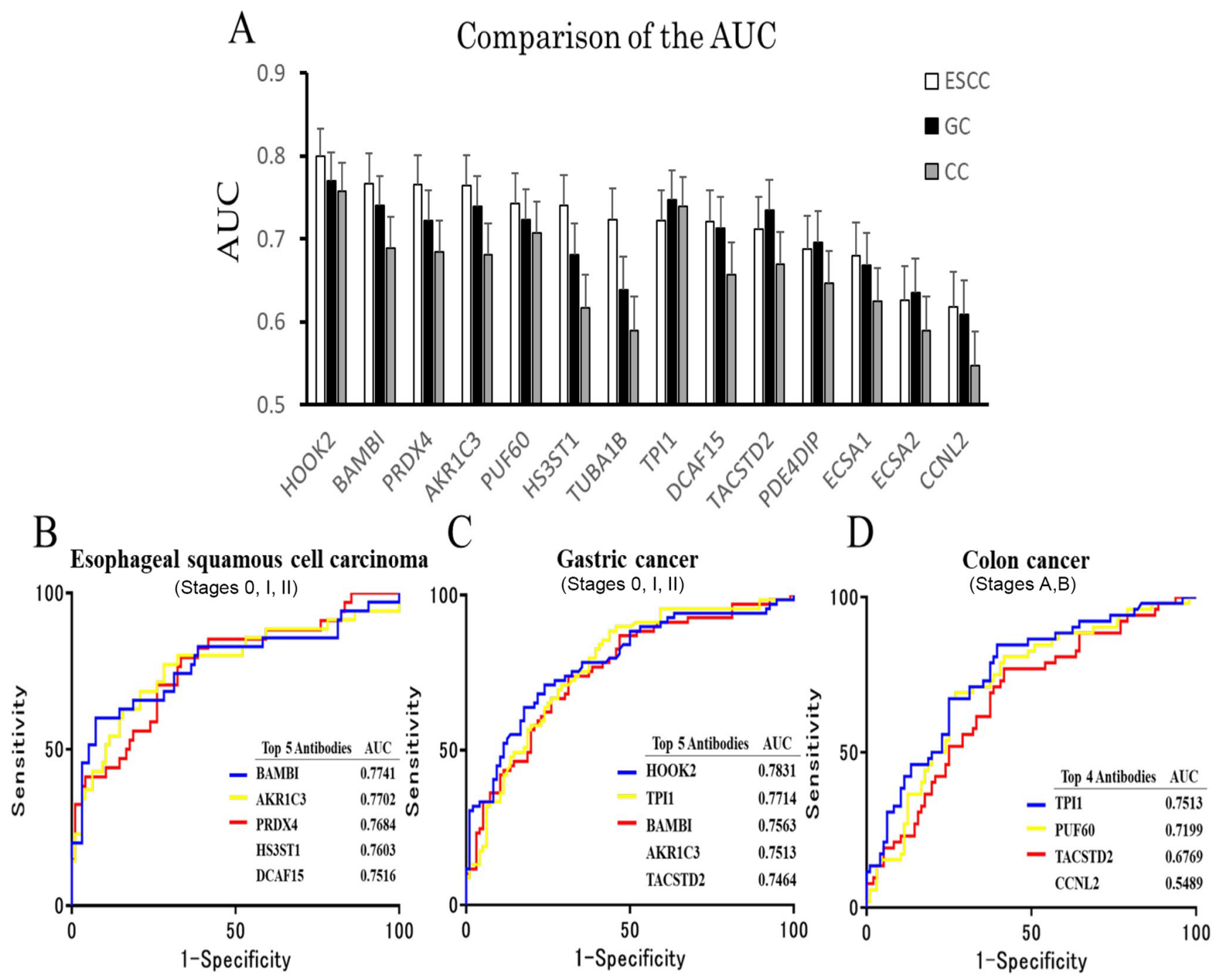

Figure 3: Comparison of the AUC by digestive organ cancer patients. (A) The overall diagnostic efficiencies of 14 antibodies were evaluated by comparing the ROC curves. The area under each ROC analysis was calculated, and the difference between ROC curves was assessed the statistical significance. $\mathrm{P}<0.05$ was considered significant. ROC curves were generated, and the area under the curve (AUC) values were calculated using the GraphPad Prism 5. The error bars represent 95\% CI (HD: $\mathrm{n}=96, \mathrm{EC}: \mathrm{n}=85, \mathrm{CC}: \mathrm{n}=96, \mathrm{GC}: \mathrm{n}$ = 97). (B, C, D) The levels of ROC analysis in healthy donors (HD), gastric cancer (GC), colon cancer (CC), and esophageal SCC (ESCC) examined by AlphaLISA are shown. Candidate markers were shown higher top 3 AUC in early stage cancers than in progressive cancers. 
AlphaLISA is an excellent method for measuring antibody levels as compared to ELISA because it has low variations, stable background, and high specificity. It does not involve plate-washing steps, but instead involves mixing of antigens with antibodies in sera followed by the addition of donor and acceptor beads. For instance, Figure 2 showed highly reproducible results, including distributions, $\mathrm{P}$ values, and positive rates despite using different sets of sera from healthy donors and patients. The precise measurement offered by AlphaLISA might enable establishment of antibody markers, although most of the existing tumor diagnosis methods involved antigen markers, with the exception of the anti-p53 marker $[2,15]$. The measurement of antibodies was more sensitive in comparison to the measurement of the antigen levels owing to the stability of $\mathrm{IgG}$ proteins and their amplification by repeated exposures to antigenic proteins. Prior to development, highly-malignant tumors could induce necrosis, leading to exposure of intracellular antigenic proteins to plasma. Therefore, using combinational antibody detection approach might enable precise tumor diagnosis. In this study, we examined and proposed some of these candidate markers for the early diagnosis of ESCC, CC, and GC. As per our knowledge, no other studies have suggested such kind of candidate markers in digestive organ cancers. Our study would be an important approach for further selecting diagnostic marker candidates for digestive organ cancers.
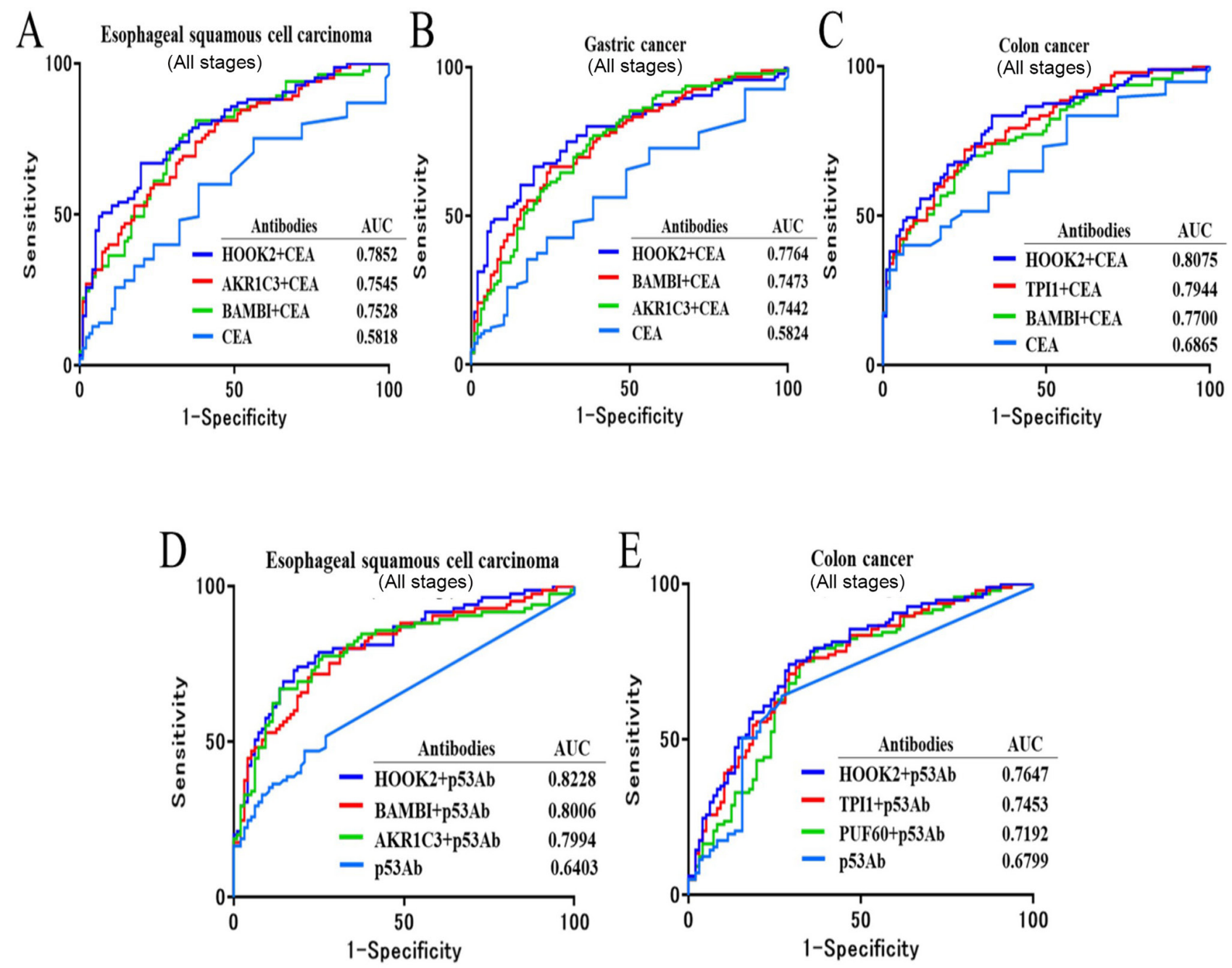

Figure 4: ROC analysis in combination of candidate markers and CEA/p53 antibody markers. The ROC analysis of detected candidate markers and two clinically used tumor markers (anti-p53 antibody, CEA) were created on the basis of the Z scores data normalized with standard deviation to the quantified Alpha count data of 277 patients with various cancers and 96 healthy subjects. Shown in descending order of AUC. Target number: $\mathrm{HD}=96, \mathrm{EC}=85, \mathrm{CC}=97, \mathrm{GC}=96$. Show the top three antibody lists. 
Table 2: The largest AUC of single or combined auto-antibodies in gastrointestinal cancers depending on the early or advanced stages

\begin{tabular}{|c|c|c|c|c|}
\hline & \multicolumn{2}{|c|}{ Early stages $(0$, I, II or $A, B)$} & \multicolumn{2}{|c|}{ Advanced stages (III, IV or C, D) } \\
\hline & Single AUC & Combined AUC & Single AUC & Combined AUC \\
\hline \multirow[t]{2}{*}{ ESCC } & HOOK2: 0.7804 & CEA+BAMBI: 0.7631 & HOOK2: 0.8119 & CEA+HOOK2: 0.7844 \\
\hline & & p53 Ab+HOOK2: 0.7985 & & p53 Ab+HOOK2: 0.8365 \\
\hline GC & HOOK2: 0.7831 & $\mathrm{CEA}+\mathrm{HOOK} 2: 0.7844$ & ECSA1: 0.7446 & CEA+ECSA1: 0.7904 \\
\hline \multirow[t]{2}{*}{$\mathrm{CC}$} & HOOK2: 0.7536 & $\mathrm{CEA}+\mathrm{HOOK} 2: 0.7406$ & HOOK2: 0.7670 & $\mathrm{CEA}+\mathrm{HOOK} 2: 0.9023$ \\
\hline & & p53 Ab+HOOK2: 0.7669 & & p53 Ab+HOOK2: 0.7889 \\
\hline
\end{tabular}

\section{MATERIALS AND METHODS}

\section{Clinical samples}

The present study was performed in accordance with "The Code of Ethics of the World Medical Association" (Declaration of Helsinki). The Local Ethical Review Board of the Chiba University, Graduate School of Medicine, and those of co-operating hospitals approved this work. Sera of patients with ESCC $(n=85)$, GC $(n=$ $96)$, and CC $(n=97)$ were obtained from the Department of Frontier Surgery, Chiba University Hospital, Chiba, Japan (Supplementary Tables 1-5). Sera of health donors (HDs) $(\mathrm{n}=96)$ were obtained from Higashi Funabashi Hospital. Written informed consent was obtained from all participants prior to this study. Each serum sample was centrifuged at $2,000 \times \mathrm{g}$ for $10 \mathrm{~min}$ and then the supernatant was stored at $-80^{\circ} \mathrm{C}$ until use. Repeated thawing and freezing of samples were avoided.

\section{Screening by expression cloning}

Recombinant DNA studies were performed with the official permission of the Chiba University Graduate School of Medicine and were carried out in accordance with the rules of the Japanese government. We used a $\lambda$ ZAP II phage cDNA library prepared from the mRNA of the T.Tn cells and a commercially available human fetal testis cDNA library (Uni-ZAP XR Premade Library, Stratagene, La Jolla, CA) to screen for clones that were immunoreactive against serum $\mathrm{IgG}$ from patients with ESCC as described in earlier studies $[16,17]$. Escherichia coli XL1-Blue MRF' was infected with $\lambda$ ZAP II or UniZAP XR phage and the expression of resident cDNA clones was induced after blotting the infected bacteria onto NitroBind nitrocellulose membranes (Osmonics, Minnetonka, MN) The above membranes had been treated with $10 \mathrm{mM}$ isopropyl- $\beta$-D-thiogalactoside (IPTG, Wako Pure Chemicals, Osaka, Japan) for $30 \mathrm{~min}$. The membranes with bacterial proteins were rinsed 3 times with TBS-T [20 mM Tris- $\mathrm{HCl}$ (pH 7.5), $0.15 \mathrm{M} \mathrm{NaCl}$, and $0.05 \%$ Tween-20], and non-specific binding was blocked by incubation with $1 \%$ protease-free bovine serum albumin (Nacalai Tesque, Inc., Kyoto, Japan) in TBS-T for $1 \mathrm{~h}$. The membranes were exposed to 1:2000-diluted sera of patients for $1 \mathrm{~h}$. After three washes with TBS-T, the membranes were incubated for $1 \mathrm{~h}$ with 1:5000-diluted alkaline phosphatase-conjugated goat anti-human IgG (Jackson ImmunResearch Laboratories, West Grove, PA). Positive reactions were developed using $100 \mathrm{mM}$ Tris$\mathrm{HCl}$ (pH 9.5) containing $100 \mathrm{mM} \mathrm{NaCl}, 5 \mathrm{mM} \mathrm{MgCl}$, $0.15 \mathrm{mg} / \mathrm{mL}$ of 5-bromo-4-chloro-3-indolylphosphate, and $0.3 \mathrm{mg} / \mathrm{mL}$ of nitro blue tetrazolium (Wako Pure Chemicals). Positive clones were re-cloned twice until obtaining monoclonality as described in previous studies $[16,18,19]$.

Monoclonal phage cDNA clones were converted to pBluescript phagemids by excision in vivo using the ExAssist helper phage (Stratagene). Plasmid pBluescript containing cDNA was obtained from the E. coli SOLR strain after transformation by the phagemid. The sequences of cDNA inserts were evaluated for homology with identified genes or proteins within the public sequence database (http://blast.ncbi.nlm.nih.gov/Blast.cgi).

\section{Expression and purification of antigen proteins}

The expression plasmids of glutathione Stransferase (GST)-fused proteins were constructed by recombining the cDNA sequences into pGEX-4T-3 (GE Healthcare Life Sciences, Pittsburgh, PA). The inserted DNA fragments were ligated in frame to pGEX4T-3 using the Ligation Convenience Kits (Nippon Gene, Toyama, Japan). Ligation mixtures were used to transform ECOS ${ }^{\mathrm{TM}}$-competent E. coli BL-21 (Nippon Gene), and appropriate recombinants were confirmed by DNA sequencing as well as protein expressions. Treating the transformed $E$. coli with $0.1 \mathrm{mM}$ IPTG for $3 \mathrm{~h}$ induced the expression of the GST-fusion proteins. The GST-fused recombinant proteins were purified by Glutathione Sepharose column chromatography according to the manufacturer's instructions (GE Healthcare Life Sciences) and dialyzed against phosphate-buffered saline as described in previous studies [20-22]. 


\section{Western blotting}

GST, GST-TPI1，GST-HOOK2，GST-PRDX4, GST-HS3ST1, GST-TUBA1B, GST-TACSTD2, GSTAKP1C3, GST-BAMBI, GST-DCAF1, GST-PDE4DIP, GST-ECSA1, GST-ECSA2, GST-CCNL2, and GSTPUF60 proteins $(0.3 \mu \mathrm{g})$ were electrophoresed through SDS-polyacrylamide gel followed by western blotting using anti-GST (Rockland, Gilbertsville, PA) or sera from patients with ESCC (No.14, No.17, No.19, and No.20). After incubation with horseradish peroxidase-conjugated secondary antibody, immunoreactivity was detected with the Immobilon (Merck Millipore, Darmstadt, Germany) as described in previous studies [23, 24].

\section{AlphaLISA (amplified luminescence proximity homogeneous assay)}

AlphaLISA was performed using 384-well microtiter plates (white opaque OptiPlate ${ }^{\mathrm{TM}}$, Perkin Elmer) containing $2.5 \mu \mathrm{L}$ of $1 / 100$-diluted sera and $2.5 \mu \mathrm{L}$ of GST or GST-fusion proteins $(10 \mu \mathrm{g} / \mathrm{mL})$ in AlphaLISA buffer (25 mM HEPES, $\mathrm{pH} 7.4,0.1 \%$ casein, $0.5 \%$ Triton X-100, $1 \mathrm{mg} / \mathrm{mL}$ dextran-500, and $0.05 \%$ Proclin-300). The reaction mixture was incubated at room temperature for 6-8 h. Next, anti-human IgG-conjugated acceptor beads $(2.5 \mu \mathrm{L}$ of $40 \mu \mathrm{g} / \mathrm{mL})$ and glutathione-conjugated donor beads $(2.5 \mu \mathrm{L}$ of $40 \mu \mathrm{g} / \mathrm{mL})$ were added and incubated further for 7-21 days at room temperature in the dark. The chemical emission was read on an EnSpire Alpha microplate reader (PerkinElmer) as previously described [25-31]. Specific reactions were calculated by subtracting Alpha values of GST control from the values of GSTfusion proteins. AlphaLISA is a registered trademark of PerkinElmer, Inc., which is shown in a website 'http:// www.perkinelmer.com/lab-solutions/resources/docs/ GDE_ELISA-to-AlphaLISA.pdf’.

\section{Statistical analyses}

All statistical analyses were carried out using the GraphPad Prism 5 (GraphPad Software, La Jolla, CA). Mann-Whitney U test was used to determine the significance of the differences between the two groups. The predictive values of markers for diseases were assessed by receiver operating curve (ROC) analysis and the cutoff values were set at the values that maximize the sums of the sensitivity and specificity. All tests were twotailed and a $P$ value below 0.05 was considered significant. We calculated antibody group-specific Z-scores for these measures to facilitate the comparison across anti-p53 antibody, CEA and antibodies groups. Z-score analysis was performed after normalization to healthy donors mean values:

$\mathrm{Z}$-score $=[($ control mean $)-($ individual value $)] /$ (control SD) $[32,33]$.
The Combined ROC analysis was performed by adding each $\mathrm{Z}$ score.

\section{Abbreviations}

AUC, area under the curve; GST, glutathione Stransferase; HD, healthy donor; IPTG, isopropyl- $\beta$-Dthiogalactoside; ROC, receiver operating curve; SEREX, serological identification of antigens by recombinant cDNA expression cloning.

\section{ACKNOWLEDGMENTS}

We thank Mr. Satoshi Fudo, Ms. Kurumi Hayashi (Department of Physical Chemistry, Chiba University, Japan), Ms. Nobuko Tanaka, and Ms. Guzhanuer Ailiken (Department of Molecular Diagnosis, Graduate School of Medicine, Chiba University) for their technical assistance, Ms. Megumi Ihato, Mr. Syuichi Yamamoto (Division of Laboratory Medicine, Chiba University Hospital, Japan) for clinical sample collection, and Mr. Hirofumi Doi (Celish FD, INC, Japan) for useful scientific discussion.

\section{CONFLICTS OF INTEREST}

The authors do not have any conflicts of interest.

\section{GRANT SUPPORT}

This work was supported, in part, by a Grant for the 21st Century COE (Center of Excellence) Program, a Grant-in-Aid of Japan Science and Technology Agency (JST), and Ministry of Education, Culture, Sports, Science and Technology (MEXT) in Japan. Japan Agency for Medical Research and Development (AMED) partly support this study.

\section{REFERENCES}

1. Kobayashi S, Hoshino T, Hiwasa T, Satoh M, Rahmutulla B, Tsuchida S, Komukai Y, Tanaka T, Matsubara H, Shimada H, Nomura F, Matsushita K. Anti-FIRs (PUF60) auto-antibodies are detected in the sera of early-stage colon cancer patients. Oncotarget. 2016;7: 82493-82503. https:// doi.org/10.18632/oncotarget.12696.

2. Shimada H, Takeda A, Arima M, Okazumi S, Matsubara H, Nabeya Y, Funami Y, Hayashi H, Gunji Y, Suzuki T, Kobayashi S, Ochiai T. Serum p53 antibody is a useful tumor marker in superficial esophageal squamous cell carcinoma. Cancer. 2000;89: 1677-1683.

3. Sahin U, Tureci O, Schmitt H, Cochlovius B, Johannes T, Schmits R, Stenner F, Luo G, Schobert I, Pfreundschuh M. Human neoplasms elicit multiple specific immune responses in the autologous host. Proc Natl Acad Sci U S A. $92 ; 1995: 11810-11813$. 
4. Cancer immunome database: http://www2.licr.org/ CancerImmunomeDB/.

5. Nakashima K, Shimada H, Ochiai T, Kuboshima M, Kuroiwa N, Okazumi S, Matsubara H, Nomura F, Takiguchi M, Hiwasa T. Serological identification of TROP2 by recombinant cDNA expression cloning using sera of patients with esophageal squamous cell carcinoma. Int $\mathrm{J}$ Cancer. 2004;112: 1029-1035.

6. Kuboshima M, Shimada H, Liu TL, Nakashima K, Nomura F, Takiguchi M, Hiwasa T, Ochiai T. Identification of a novel SEREX antigen, SLC2A1/GLUT1, in esophageal squamous cell carcinoma. Int J Oncol. 2006;28: 463-468.

7. Kuboshima M, Shimada H, Liu TL, Nomura F, Takiguchi M, Hiwasa T, Ochiai T. Presence of serum tripartite motifcontaining 21 antibodies in patients with esophageal squamous cell carcinoma. Cancer Sci. 2006;97: 380-386.

8. Shimada H, Shiratori T, Yasuraok M, Kagaya A, Kuboshima M, Nomura F, Takiguchi M, Ochiai T, Matsubara H, Hiwasa T. (2009) Identification of Makorin 1 as a novel SEREX antigen of esophageal squamous cell carcinoma. BMC Cancer. 2009;9: 232.

9. Shimada H, Nakashima K, Ochiai T, Nabeya Y, Takiguchi M, Nomura F, Hiwasa T. Serological identification of tumor antigens of esophageal squamous cell carcinoma. Int $\mathrm{J}$ Oncol. 2005;26: 77-86.

10. Shimada H, Kuboshima M, Shiratori T, Nabeya Y, Takeuchi A, Takagi H, Nomura F, Takiguchi M, Ochiai T, Hiwasa T. Serum anti-myomegalin antibodies in patients with esophageal squamous cell carcinoma. Int J Oncol. 2007;30: 97-103.

11. Hiwasa T, Shimada H, Ochiai T, Takiguchi M. (2006). Serological identification of antigens by recombinant cDNA expression cloning (SEREX) using antibodies from patients with esophageal squamous cell carcinoma. In: Moleculomics and Thereafter (Hiwasa T, ed.). Kerala, India, Research Signpost, pp. 99-117.

12. Kagaya A, Shimada H, Shiratori T, Kuboshima M, Nakashima-Fujita K, Yasuraoka M, Nishimori T, Kurei S, Hachiya T, Murakami A, Tamura Y, Nomura F, Ochiai $\mathrm{T}$, et al. Identification of a novel SEREX antigen family, ECSA, in esophageal squamous cell carcinoma. Proteome Sci. 2011;9: 31.

13. Matsushita K, Tomonaga T, Shimada H, Shioya A, Higashi M, Matsubara H, Harigaya K, Nomura F, Libutti D, Levens D, Ochiai T. An essential role of alternative splicing of c-myc suppressor FUSE-binding protein-interacting repressor in carcinogenesis. Cancer Res. 2006;66: 1409-1417.

14. Rahmutulla B, Matsushita K, Satoh M, Seimiya M, Tsuchida S, Kubo S, Shimada H, Ohtsuka M, Miyazaki M, Nomura F. Alternative splicing of FBP-interacting repressor coordinates c-Myc, P27Kip1/cyclinE and Ku86/XRCC5 expression as a molecular sensor for bleomycin-induced DNA damage pathway. Oncotarget. 2014;5: 2404-2417. https://doi.org/10.18632/oncotarget.1650.
15. Shimada H, Yajima S, Oshima Y, Hiwasa T, Tagawa M, Matsushita K, Nomura F. Impact of serum biomarkers on esophageal squamous cell carcinoma. Esophagus. 2012;9: 131-140.

16. Shimada H, Ito M, Kagaya A, Shiratori T, Kuboshima M, Suzuki M, Liu TL, Nabeya Y, Matsubara H, Matsushita K, Nomura F, Takiguchi M, Hiwasa T. Elevated serum antibody levels against cyclin L2 in patients with esophageal squamous cell carcinoma. J Cancer Sci Ther. 2015; 7: 60-66.

17. Ohno S, Akira Y, Konno Y, Imajoh S, Suzuki K. A novel phorbol ester receptor/protein kinase, nPKC, distantly related to the protein kinase C family. Cell. 1998;53: 731-741.

18. Jiang P, Du W, Heese K, Wu M. The Bad guy cooperates with good cop p53: Bad is transcriptionally up-regulated by $\mathrm{p} 53$ and forms a Bad/p53 complex at the mitochondria to induce apoptosis. Mol Cell Biol. 2006;26: 9071-9082.

19. Machida T, Kubota M, Kobayashi E, Iwadate Y, Saeki N, Yamaura A, Nomura F, Takiguchi M, Hiwasa T. Identification of stroke-associated-antigens via screening of recombinant proteins from the human expression cDNA library (SEREX). J Translat Med. 2015;13: 71.

20. Miyashita T, Reed JC. Tumor suppressor p53 is a direct transcriptional activator of the human bax gene. Cell. 1995;80: 293-299.

21. Shimada H, Liu TL, Ochiai T, Shimizu T, Haupt Y, Hamada H, Abe T, Oka M, Takiguchi M, Hiwasa T. Facilitation of adenoviral wild-type p53-induced apoptotic cell death by overexpression of p33ING1 in T.Tn human esophageal carcinoma cells. Oncogene. 2002;21: 1208-1216.

22. Matsutani T, Hiwasa T, Takiguchi M, Oide T, Kunimatsu M, Saeki N, Iwadate Y. Autologous antibody to src-homology 3-domain GRB2-like 1 specifically increases in the sera of patients with low-grade gliomas. J Exp Clin Cancer Res. 2012;31: 85 .

23. Oda E, Ohki R, Murasawa H, Nemoto J, Shibue T, Yamashita T, Tokino T, Taniguchi T, Tanaka N. Noxa, a BH3-only member of the Bcl-2 family and candidate mediator of p53-induced apoptosis. Science. 2000;288: 1053-1058.

24. Sekiya T, Fushimi M, Mori H, Hirohashi S, Nishimura S, Sugimura T. Molecular cloning and the total nucleotide sequence of the human c-Ha-ras-1 gene activated in melanoma from a Japanese patient. Proc Natl Acad Sci U S A. 1998;81: 4771-4775.

25. Takahashi K, Kanazawa H, Chan H, Hosono T, Takahara M, Sato KI. A case of esophageal carcinoma metastatic to the mandible and characterization of two cell lines (T.T. and T.Tn.) established from the oral tumor. Jpn J Oral Maxillofac Surg. 1990;36: 307-316.

26. Hiwasa T, Shimada H, Sakaida T, Kitagawa M, Kuroiwa N, Ochiai T, Takiguchi M. Drug-sensitivity pattern analysis of study of functional relationship between gene products. FEBS Lett. 2003;552: 177-183. 
27. Hiwasa T, Zhang XM, Kimura R, Machida T, Kitamura K, Yamazoe R, Kunimatsu M, Mine S, Kobayashi E, Iwadate Y, Saeki N, Takemoto M, Kobayashi K, et al. (2015) Association of serum antibody levels against TUBB2C with diabetes and cerebral infarction. Integ Biomed Sci. 2015;1: 49-63.

28. Goto K, Sugiyama T, Matsumura R, Zhang XM, Kimura R, Taira A, Arita E, Iwase K, Kobayashi E, Iwadate Y, Saeki N, Mori M, Uzawa A, et al. Identification of cerebral infarction-specific antibody markers from autoantibodies detected in patients with systemic lupus erythematosus. J Mol Biomark Diagnos. 2015;6: 2.

29. Hiwasa T, Machida T, Zhang XM, Kimura R, Wang H, Iwase K, Ashino H, Taira A, Arita E, Mine S, Ohno M, Chen PM, Nishi E, et al. Elevated levels of autoantibodies against ATP2B4 and BMP-1 in sera of patients with atherosclerosis-related diseases. Immunome Res. 2015;11: 097.

30. Nakamura R, Tomiyoshi G, Shinmen N, Kuroda H, Kudo T, Doi H, Mine S, Machida T, Ikuo K, Wada T, Aotsuka A, Kobayashi E, Yoshida Y, et al. An anti-deoxyhypusine synthase antibody as a marker of atherosclerosis-related cerebral infarction, myocardial infarction, diabetes mellitus, and chronic kidney disease. SM Atheroscler J. 2017;1: 1001.

31. Hiwasa T, Tomiyoshi G, Nakamura R, Shinmen N, Kuroda H, Kunimatsu M, Mine S, Machida T, Sato E, Takemoto M, Hattori A, Kobayashi K, Kawamura H, et al. Serum SH3BP5-specific antibody level is a biomarker of atherosclerosis. Immunome Res 2017;13: 132.

32. Chiu RW, Chan KC, Gao Y, Lau VY, Zheng W, Leung TY, Foo CH, Xie B, Tsui NB, Lun FM, Zee BC, Lau TK, Cantor CR, Lo YM. Noninvasive prenatal diagnosis of fetal chromosomal aneuploidy by massively parallel genomic sequencing of DNA in maternal plasma. Proc Natl Acad Sci U S A. 2008;105: 20458-20463.

33. Matsuda $H$, Mizumura $S$, Nagao $T$, Ota $T$, Iizuka $T$, Nemoto K, Takemura N, Arai H, Homma A. Automated discrimination between very early Alzheimer disease and controls using an easy Z-score imaging system for multicenter brain perfusion single-photon emission tomography. AJNR Am J Neuroradiol. 2007;28: 731-736. 